Letters to the editor

\title{
Tuberculosis compulsory treatment: advancement or retrogression?
}

Considering that tuberculosis ( $\mathrm{Tb}$ ) still kills approximately 3 million people per year in the world and it is the third infectious disease in the number of people killed, several reflections are valid to improve the drop-outs, which are the main problem of the programs of tuberculosis control, since the treatment schedules currently available are highly efficient.

Since 1993, tuberculosis control was pointed out as a worldwide emergency situation by the World Health Organization (WHO). Goals were established to cure $85 \%$ of the new cases, to diagnose $70 \%$ of the new patients in 2005 and to reduce the mortality in $50 \%$ in 2010.

In 1963, Fox ${ }^{(1)}$, admitted that the regularity and efficacy of the schedule used were of major importance, and Addington ${ }^{(2)}$, in 1979 considered treatment drop-out as the most severe problem in tuberculosis control.

WHO recommends the administration of medicines by means of directly observed therapy (DOT), i.e., observing the patient swallowing the medication. Later on, according to local conditions, this WHO method was transformed into DOTS strategy (directly observed therapy short-course), which should be adapted to each particular local condition ${ }^{(3,4)}$.

Therefore DOTS strategy should fulfill five basic rules: 1) government involvement with Tuberculosis Program/trained and interested working team, 2) laboratory net with equipment and qualified human resources (BAAR research), 3) to administer and observe the patient swallowing the medication, 4) supply of free medication for treatment (including rifampicin), 5) information system to monitor the cases, their treatment, evolution and results ${ }^{(3,5,6)}$.

DOTS experience in NY, from 1992 to 1995, showed a substantial improvement in the local tuberculosis control program, reducing the incidence of new cases in $35 \%$ and the incidence of multi-resistant tuberculosis cases in $75 \%$, with a cost of approximately 40 million dollars to treat 3.000 patients ${ }^{(7,8)}$. DOTS-related and autoadministrated treatment cost analyses showed the advantage of DOTS, taking into consideration the early reduction of transmission, increased number of cured cases, early detection of drop-outs and reduction of cases of multiresistant tuberculosis ${ }^{(9,10)}$.

Dots treatment quickly spread to other states in the U.S. However, even placing almost $90 \%$ of tuberculosis patients in the DOTS strategy in the USA, approximately $18 \%$ do not adhere ${ }^{(11)}$. Simultaneous studies on tuberculosis transmission confirmed by means of molecular biology, new $\mathrm{Tb}$ cases coming from strain of nonadherent patients. With the concern of being able to also treat the non-adherent patients with DOTS, New York was the first U.S. state to develop quarantine laws ${ }^{(7)}$.

According to a metanalysis on DOTS, four studies used involuntatory hospitalizations for non-adherent patients in 2000 (New York, Baltimore, South Carolina and Tarrant) ${ }^{(12)}$.

New York City Health Code, of April 1993, states that all patients with Tb or suspected to have Tb must: be examined; complete treatment for Tb; adhere to a DOT program (or CoDOT, when administered by a justice commissary; be retained throughout the transmission period and be restrained even without active infection, until the cure, if necessary, and when other more reasonable treatment alternatives failed ${ }^{(7)}$. Therefore, renitent patients were treated under a CoDOTS system or admitted to "closed" hospitals specifically directed towards this purpose, they were "released" to DOTS when the adherence to the treatment improved and there were no risk of bacillus transmission to the community ${ }^{(13)}$.

Thus, in the Denver Program of Tuberculosis Control, 5\% of the patients were treated in a "closed" hospital plan due to their non-adherence, and in $5 \%$ of these patients there was a loss of follow-up, and if these patients were found, they became candidates to a new compulsory hospitalization ${ }^{(13)}$. In New York and South Carolina, less than $1 \%$ of the patients was compulsorily admitted. In Tarrant, Texas, $6.2 \%$ were submitted to compulsory hospitalization or put in quarantine due to non-adherence. The existence of regional differences in DOTS and confinement criteria must be emphasized, and that in all cases of compulsory hospitalization there was a predominance of alcoholic, psychiatric, homeless and drug addict patients ${ }^{(14)}$. 
According to Sbarbaro (1977) ${ }^{(15)}$, Tb is not an individual, but a social disease, that spreads through the air to other members of society (without their consent or knowledge); it is preventable and curable, if diagnosed and treated correctly and, therefore, treatment success depends on a responsible Health Department.

Based on these assumptions and in the cost of non-adherence ("pay now or pay much more later"), there are current laws that foresee compulsory hospitalization in all 50 American States ${ }^{(16)}$.

In Brazil, considering the worse social conditions and poverty and lower cure rates and abandonment, several strategies to warrant cure and to reduce these patient's drop-outs must still be used in renitent patients, emphasizing that we must initially assure the best program conditions.

The National Program of Tuberculosis Control attempts to equip the municipalities to increase the detection of new cases, and therefore created the Law 3739, providing financial incentive to the districts for each cure-related discharge of patients.

In the large urban centers, decentralized attendance, trained teams and longer assistance hours, especially for patients who work, would warrant the administration of supervised treatment, adapted according to the local conditions, stressing the daily supervision in the first two months of treatment, and the supervision twice/week from the third to the sixth month. In places with Family Health Program, the supervised treatment could be assured by means of health community agents to confirm that the patient swallowed the medication.

Other measures, such as patients' education, transportation tickets and basic food supply help to increase adherence to the treatment. In fact, any incentive incorporated to the current practice helps to increase the adherence ${ }^{(17)}$.

For renitent patients, judicial measurements may be adopted. Family and Children's Courts usually respond well to this demand, as long as it is proved that children are not receiving the essential medication from their parents or that children are at risk of getting tuberculous. Forensic teams, in addition to the lawyer, social workers, psychologists, have expert physicians to investigate these cases and renitent patients can even be dealt with by means of a judicial compulsory hospitalization.

It must be emphasized that compulsory hospitalization will occur only after all previously discussed measures have been tried. It should also be stresses that beds currently available to tuberculosis in the hospitals have a high rate of releases either by request or insubordination, reflecting that much more must be done to improve our strategy. The commitment of several health professionals in these hospitals must be valued, including occupational therapy, social work, concomitant treatment of alcoholism and drug abuse. The exchange between these hospitals and the basic health system is necessary, in order to monitor these patients' evolution to ambulatory treatment, assuring the continuity of the work carried out by the multiprofessional team in the hospitals.

\author{
SANDRA APARECIDA RIBEIRO \\ Associate Professor of Clinical Preventive Medicine \\ Department of Preventive Medicine \\ Universidade Federal de São Paulo \\ Phone: (55-11) 5576-4518; fax: (55-11) 5549-5159 \\ E-mail: sandrarib@medprev.epm.br
}

\title{
REFERENCES
}

1. Fox W. The economic aspects of the therapy of tuberculosis in developing countries. XVII Conférence de la Tuberculose. Roma, setembro, 1963. Bull UICT 1964;35:275-81.

2. Addington WW. Patient compliance: the most serious remaining problem in the control of tuberculosis in United States. Chest 1979;76 (Suppl):741-43.

3. An expanded DOTS framework for effective tuberculosis control. http://www.who.int/gtb.

4. Dye C. Tuberculosis 2000-2010: control, but not elimination. Int J Tuberc Lung Dis 2000;4:S146-S152.

5. Chaulk CP, Moore-Rice K, Rizzo R, Chaisson RE. Eleven years of community-based directly observed therapy for tuberculosis. JAMA 1995; 274:945-51.

6. Weis SE. Universal directly observed therapy. A treatment strategy for tuberculosis. Clin in Chest Med 1997;18:155-63.

7. Fujiwara PI, Larkin C, Frieden TR. Directly observed therapy in New York City. History, implementation, results, and challenges. Clin Chest Med 1997; 18:135-48.

8. Weis SE, Slocum PC, Blais FX, King B, Nunn M, Matney B, Gomez E, Foresman BH. The effect of directly observed therapy on the rates of drug resistance and relapse in tuberculosis. N Engl J Med 1994;330: 1179-94.

9. Burman WJ, Dalton CB, Cohn DL, Butler JRG, Reves RR. A cost-effectiveness analysis of directly observed therapy vs selfadministered therapy for treatment of tuberculosis. Chest 1997;12:63-70. 
10. Floyd K, Wilkinson D, Gilks C. Comparison of cost effectiveness of directly observed treatment (DOT) and conventionally delivered treatment for tuberculosis: experience from rural South Africa. Br Med J 1997;315:1407-11.

11. Burman WJ, Cohn DL, Rietmeijer CA, Judson FN, Sbarbaro JA, Reves RR. Short-term incarceration for the management of noncompliance with tuberculosis treatment. Chest 997;112:57-62.

12. Volmink J, Matchaba P, Garner P. Directly observed therapy and treatment adherence. Lancet 2000;355:1345-50.

13. Chaulk CP, Pope DS. The Baltimore City Health Department Program of directly observed therapy for tuberculosis. Clin Chest Med 1997;18:149-54.

14. Pablos-Mendez A, Knirsch CA, Graham Barr R, Lerner BH, Frieden TR. Nonadherence in tuberculosis treatment: predictors and consequences in New York City. Am J Med 1997;102:164-70.

15. Sbarbaro J. Directly observed therapy - Who is responsible? Clin Chest Med 1997;18:131-3.

16. Morse DI. Directly observed therapy for tuberculosis. Spend now or pay later. BMJ 1996;312:719-20.

17. Dalcomo, MMP. Regime de curta duração, intermitente e parcialmente supervisionado, como estratégia de redução do abandono no tratamento da Tuberculose no Brasil [Tese de Doutorado]. Unifesp, São Paulo, 2000;136f. 